\title{
Enteric parasites can disturb leptin and adiponectin levels in children
}

\author{
Raida S. Yahya ${ }^{1}$, Soha I. Awad ${ }^{2,3}$, Nadeem Kizilbash ${ }^{4}$, Hatim A. El-Baz ${ }^{5,6}$, Gehan Atia ${ }^{7}$
}

\author{
'Department of Laboratory Medicine, Children's' Hospital, Faculty of Medicine, \\ Mansoura University, Egypt \\ 2Department of Parasitology, Faculty of Medicine, Mansoura, Egypt \\ ${ }^{3}$ Department of Medical Parasitology, Faculty of Medicine and Applied Medical \\ Sciences, Northern Border University, Saudi Arabia \\ ${ }^{4}$ Department of Biochemistry, Faculty of Medicine and Applied Medical Sciences, \\ Northern Border University, Arar, Saudi Arabia \\ ${ }^{5}$ Department of Biochemistry, National Research Centre, Cairo, Egypt \\ ${ }^{6}$ Department of Clinical Biochemistry, Faculty of Medicine, King Abdulaziz University \\ (North Jeddah Branch), Saudi Arabia \\ ${ }^{7}$ Department of Pediatrics, Children Hospital, Faculty of Medicine, Mansoura, Egypt
}

Submitted: 16 March 2015

Accepted: 1 August 2015

Arch Med Sci 2018; 14, 1: 101-106

DOI: $10.5114 /$ aoms.2016.60707

Copyright @ 2016 Termedia \& Banach

\section{Abstract}

Introduction: Infection by intestinal parasites in childhood may be the main cause of many health-related problems in developed countries such as anemia, anorexia, loss of appetite, retarded growth and development. The aim of the present study was to assess the effect of different intestinal parasites on white adipose tissue hormones.

Material and methods: Eighty-one children infected by different parasites and 35 apparently healthy children were enrolled in this study. All patients and controls were subjected to clinical examination, measurement of body mass index (BMI) and laboratory examination.

Results: For BMI percentiles, there was a significant increase in serum leptin level $(p=0.042)$ and a significant decrease in serum adiponectin level ( $p=$ 0.039 ) in uninfected children, whereas there were no significant changes in the infected group ( $p=0.068$ and 0.082 respectively). A significant increase in leptin and decrease in adiponectin levels were observed for E. histolytica, Strongyloides and E. histolytica and Giardia infections compared to the control group ( $p=0.047,0.035$ and 0.019 for leptin, and $p=0.025,0.038$ and 0.041 for adiponectin, respectively).

Conclusions: The infection by some intestinal parasites may deregulate the secretion of leptin and adiponectin and also affect the absorption of some nutrients which can disturb the BMI and cause anorexia.

Key words: leptin, adiponectin, Entamoeba histolytica, Strongyloides stercoralis, anorexia, body mass index.

\section{Introduction}

Parasitosis has an enormous impact all over the world since helminth infections affect about a billion people [1]. Schistosomiasis affects 200 million people, while 400 million schoolchildren harbor other intestinal parasites [2]. Intestinal parasites are associated with anorexia, malabsorption, weight loss, malnutrition and anemia. The potential impact of diarrhea on nutritional status is well known, and there exists a syner-

\author{
Corresponding author: \\ Nadeem Abbas Kizilbash PhD \\ Faculty of Medicine \\ and Applied Medical Sciences \\ Northern Border University \\ 91431 Arar, Saudi Arabia \\ Phone: +966592390610 \\ E-mail: fsd707@gmail.com
}


gistic relationship between diarrhea and malnutrition [3].

Intestinal mucosal infection by parasites activates mesenteric lymph nodes which are adjacent to adipose tissue. So once the lymph nodes are activated, the adipocytes respond by releasing the so-called adipocytokines to supply energy for the functioning of the lymph nodes [4].

The fecal-oral transmission of Entamoeba histolytica usually involves contaminated food or water [5]. The factors that can lead to tissue invasion by E. histolytica are poorly understood [6]. Virulent $E$. histolytica strains can infect intact intestinal mucosa. This infection does not require pre-existing mucosal damage.

Leptin and adiponectin are included among adipocytokines [7]. Leptin is a $16 \mathrm{kDa}$ protein encoded by the ob gene [8]. Leptin is a pleiotropic cytokine-like hormone affecting immunologic reactions and hormone axis regulation [9]. In fact, leptin acts at the hypothalamus level and plays an important role in regulating energy production and expenditure, appetite and hunger, metabolism, and behavior [10]. It is one of the most important hormones that is produced by the adipose tissue [11]. Leptin functions by binding to the leptin receptor. Leptin is released locally within the intestinal mucosa and is implicated in interactions with pro-inflammatory cytokines to control local inflammations [12].

Adiponectin is a $30 \mathrm{kDa}$ protein product of the adipose most abundant gene transcript 1 (apM1) gene with high structural similarity to collagen VIII, X, and complement C1q [13]. Adiponectin has a role in the regulation of energy homeostasis [14]. Adiponectin modulates glucose regulation and fatty acid oxidation [15]. It is secreted from the adipose tissue into the bloodstream and is abundant in the plasma [16]. Levels of adiponectin are inversely related to body fat percentage in adults [17]. The association in infants and young children is less clear.

Infection of some types of intestinal parasites (Entamoeba histolytica and Strongyloides) can deregulate the secretion of leptin and adiponectin levels and also affect the absorption of some nutrients, which can disturb the body mass index (BMI) and cause anorexia. Parasite-induced anorexia is an acute phase response to infection [18] which is also mediated via cytokine induction of leptin synthesis [19]. This case control study employed 81 pediatric subjects with different parasitic infections and 35 control subjects to elucidate the relation of leptin and adiponectin in children with parasite-induced malnutrition.

\section{Material and methods}

The procedures followed in this case control study on pediatric subjects were in accordance with the ethical standards of the responsible com- mittee on human experimentation (institutional and national) and with the Helsinki Declaration of 1975, as revised in 2000 .

\section{Biometric data}

Eighty-one children with parasitic infections, selected from Mansoura University Children Hospital, were enrolled in this study. There were 46 (39.7\%) males and 17 (60.3\%) females with ages ranging from one to 15 years. Thirty-five apparently healthy volunteers - 15 males (43\%) and 20 (57\%) females, aged from 5 to 12 years - were taken as controls. Written consent was obtained from parents of children. Height and weight were measured using a portable free-standing stadiometer and an electronic weighing scale (BS-8001). In measurement of weight, each participant was made to stand still in an upright position on the scale. Weight was recorded to the nearest $0.1 \mathrm{~kg}$, whilst height was recorded to the nearest $0.5 \mathrm{~cm}$. Body mass index was calculated as weight $(\mathrm{kg}) \mathrm{di}$ vided by the square of height $(\mathrm{m})$. Based on the Centers for Disease Control and Prevention (U.S.A.) growth charts, BMI was defined at the following levels: normal weight $\left(10^{\text {th }}\right.$ percentile $\leq \mathrm{BMI} \leq 90^{\text {th }}$ percentile), underweight (BMI $<10^{\text {th }}$ percentile), overweight and obese (BMI $>90^{\text {th }}$ percentile).

\section{Serum testing}

Serum level of glucose and lipid profile were measured using a fully automated clinical analyzer (Biolis 24i Premium, Tokyo, Boeki Machinery, Japan). Serum level of leptin was measured using the DRG leptin Sandwich enzyme-linked immunosorbent assay kit [20] (DRG Diagnostics, GmbH, Germany) and serum level of adiponectin using the Ray Bio R Human Adiponectin/Acrp30 ELISA kit [21] (Ray Biotech, Inc. USA). For stool examination, direct smear, the formol-ether concentration method [22] and acid fast stain were used for Coccidea [23]. Gomori's trichrome stain [24] and Weber's trichrome stain for Microsporidia [25] and agar plate culture for Strongyloides stercoralis [26] were used.

\section{Stool testing}

The presence of E. histolytica/E. dispar trophozoites in stool samples was demonstrated by enzyme-linked immunosorbent assay (ELISA) (E histolytica Test TechLab, Blacksburg, VA, USA). Only fresh samples, obtained no more than $48 \mathrm{~h}$ prior to testing, were used. No specimens treated with formalin or any other preservative (SAF or PVA) were included [27].

\section{Statistical analysis}

Exclusion criteria for the study included patients receiving drugs with known anti-hyperlip- 
Table I. Serum leptin and adiponectin levels in infected children and controls according to BMI percentiles

\begin{tabular}{|c|c|c|c|c|c|c|}
\hline Group & BMI & $N$ & Leptin & $P$-value & Adiponectin & $P$-value \\
\hline \multirow[t]{3}{*}{ Controls } & Under weight & 10 & $1.38 \pm 0.87$ & \multirow[t]{3}{*}{0.042} & $8.99 \pm 2.45$ & \multirow[t]{3}{*}{0.039} \\
\hline & Normal weight & 15 & $2.15 \pm 1.68$ & & $7.97 \pm 0.34$ & \\
\hline & Over weight & 10 & $3.25 \pm 0.78$ & & $6.70 \pm 0.68$ & \\
\hline \multirow[t]{3}{*}{ Patients } & Under weight & 27 & $2.30 \pm 1.37$ & \multirow[t]{3}{*}{0.068} & $8.10 \pm 2.80$ & \multirow[t]{3}{*}{0.082} \\
\hline & Normal weight & 36 & $2.51 \pm 1.37$ & & $6.05 \pm 3.02$ & \\
\hline & Over weight & 18 & $3.43 \pm 2.10$ & & $5.60 \pm 2.89$ & \\
\hline
\end{tabular}

idemic effect, patients exhibiting thyroid function disorder, patients suffering from diabetes mellitus (DM) and cardiovascular disease. The data was analyzed using the SPSS program, standard version 16. Quantitative data is presented as mean \pm standard deviation. Student's $t$-test and ANOVA were used to compare the means. Correlations between variables were evaluated by Pearson's correlation study and a $p$-value $\leq 0.05$ was considered to be statistically significant.

\section{Results}

Table I shows a significant increase in serum leptin level ( $p=0.042)$ and a significant decrease in serum adiponectin level $(p=0.039)$ concerning the $\mathrm{BMI}$ percentile in uninfected children but no significant change was found in the group of infected children ( $p=0.068$ and 0.082 respectively). Figure 1 shows a negative correlation between leptin and adiponectin levels in the patient group $(r=-0.415, p=0.001)$. A significant increase of leptin level and a significant decrease of adiponectin level (Table II) were observed in E. histolytica, Strongyloides and both E. histolytica and Giardia infections compared to the control group $(p=$ $0.047,0.035$ and 0.019 for leptin and $p=0.025$, 0.038 and 0.041 for adiponectin respectively).

The study found a positive correlation between leptin and fasting blood glucose in both patients $(r=0.564, p=0.045)$ and controls $(r=0.783$,

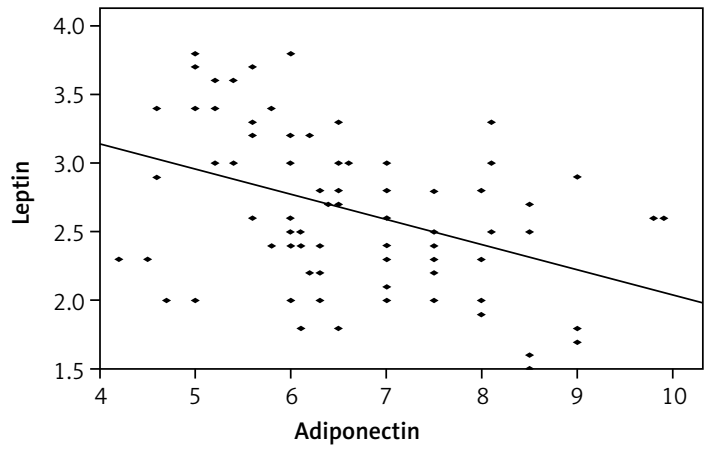

Figure 1. Correlation between leptin and adeponectin levels in patient group

$p=0.016)$ and a negative correlation between adiponectin and fasting blood glucose in both patients $(r=-0.690, p=0.037)$ and controls $(r=-0.574, p=0.021)$ (Table III). Also, plasma leptin concentration had a positive correlation with cholesterol, triglyceride and low-density lipoprotein cholesterol (LDL-C) but a negative correlation with high-density lipoprotein cholesterol (HDL-C) in both the patient group $(r=0.693, p=$ $0.043 ; r=0.784, p=0.005 ; r=0.563, p=0.021$; $r=-0.583, p=0.003$ respectively) and controls $(r=0.654, p=0.014 ; r=0.654, p=0.038 ; r=$ $0.429, p=0.000 ; r=-0.660, p=0.050$ respectively). On the other hand, plasma adiponectin concentration had a negative correlation with cholesterol, triglyceride and LDL-C but a positive correlation with HDL-C in both the patient

Table II. Serum leptin and adiponectin concentrations in different parasitic infections

\begin{tabular}{|c|c|c|c|c|c|}
\hline Parameter & $N$ & $\begin{array}{l}\text { Leptin } \\
\text { [ng/ml] }\end{array}$ & $P$-value & $\begin{array}{l}\text { Adiponectin } \\
{[\mu \mathrm{g} / \mathrm{ml}]}\end{array}$ & $P$-value \\
\hline Controls & 35 & $2.35 \pm 1.03$ & & $7.81 \pm 1.96$ & \\
\hline Entamoeba histolytica & 41 & $2.84 \pm 1.27$ & 0.047 & $5.43 \pm 2.60$ & 0.025 \\
\hline Giardia lamblia & 8 & $2.15 \pm 0.10$ & 0.088 & $7.43 \pm 2.60$ & 0.091 \\
\hline Strongyloides stercoralis & 6 & $3.09 \pm 2.30$ & 0.035 & $5.92 \pm 0.48$ & 0.038 \\
\hline Hymenolepis nana & 6 & $2.25 \pm 0.35$ & 0.125 & $6.92 \pm 1.48$ & 0.080 \\
\hline Oxyuris & 10 & $2.51 \pm 0.09$ & 0.069 & $7.97 \pm 3.16$ & 0.103 \\
\hline Entamoeba histolytica and Giardia & 10 & $3.85 \pm 0.05$ & 0.019 & $5.94 \pm 2.81$ & 0.041 \\
\hline
\end{tabular}


Table III. Correlation between leptin and adiponectin with percentile BMI, fasting blood glucose level, cholesterol level, TG level, HDL-C level and LDL-C level

\begin{tabular}{|lcccc|}
\hline Variable & \multicolumn{2}{c}{ Leptin } & \multicolumn{2}{c|}{ Adiponectin } \\
\cline { 2 - 5 } & Patients & Control & Patients & Control \\
\hline BMI percentile & $r=0.086$ & $r=0.786$ & $r=-0.035$ & $r=-0.532$ \\
& $p=0.987$ & $p=0.001$ & $p=0.159$ & $p=0.032$ \\
\hline Fasting blood glucose & $r=0.564$ & $r=0.783$ & $r=-0.690$ & $r=-0.574$ \\
& $p=0.045$ & $p=0.016$ & $p=0.037$ & $p=0.021$ \\
\hline Cholesterol & $r=0.693$ & $r=0.654$ & $r=-0.531$ & $r=-0.664$ \\
& $p=0.043$ & $p=0.014$ & $p=0.001$ & $p=0.041$ \\
\hline Triglyceride (TG) & $r=0.784$ & $r=0.654$ & $r=-0.765$ & $r=-0.951$ \\
& $p=0.005$ & $p=0.038$ & $p=0.030$ & $p=0.021$ \\
\hline HDL-C & $r=-0.583$ & $r=-0.660$ & $r=0.559$ & $r=0.631$ \\
& $p=0.003$ & $p=0.050$ & $p=0.002$ & $p=0.044$ \\
\hline LDL-C & $r=0.563$ & $r=0.429$ & $r=-0.884$ & $r=-0.894$ \\
& $p=0.021$ & $p<0.001$ & $p=0.008$ & $p=0.021$ \\
\hline
\end{tabular}

group $(r=-0.531, p=0.01 ; r=-0.765, p=0.030$ $r=-0.884, p=0.008 ; r=0.559, p=0.002$ respectively) and controls ( $r=-0.664, p=0.041$; $r=-0.951, p=0.021 ; r=-0.894, p=0.021 ; r=$ $0.631, p=0.044)$.

\section{Discussion}

Leptin and its receptor are present in the human gastric mucosa. In the human stomach, leptin is produced by the pepsinogen-secreting chief cells of the fundic mucosa. In terms of physiological function, gastric leptin may be involved in the short-term control of satiety, acting in synergy with cholecystokinin (CCK) via vagal afferent fibers in rats [28]. Leptin is secreted into the gastric juice and has a biological effect on food digestion and absorption [29].

The results show that there is a direct relationship between infection and malnutrition (indicated by a low BMI percentile). Indeed, the prevalence of underweight is increasing in the world. This might be due to greater concern about body image among children and adolescents, consuming foods with low nutritional value and also infection [30]. Infection leads to reduced dietary intake and intestinal absorption, while malnutrition leads to infection by inducing alterations in host immune function [2]. Adipose tissue has an active role in regulating energy homeostasis, lipid and glucose metabolism as well as autoimmunity and inflammatory processes [31]. The adipocytokines adiponectin and leptin have emerged as the most abundant adipocyte products that link nutrition to immunity [12, 32].

In the present study, there was a significant positive correlation between leptin and BMI percentile in uninfected children, but this significant correlation disappeared in the group of infected children. This agreed with Lõhmus et al. [33], who claimed a possible effect of parasites on leptin secretion. On the other hand, many experimental studies have shown that leptin levels increase during parasitic infection [34]. This contradictory result may be due to, in children, serum leptin levels being low in many forms of malnutrition; and then those children are susceptible to opportunistic infection [35].

A significant negative correlation between adiponectin and BMI percentile is also observed in uninfected children, but this is not observed in infected children. Matsubara et al. [36] also observed that serum adiponectin levels are reduced in obesity and plasma adiponectin concentration was inversely correlated with leptin concentrations in nondiabetic normal weight and obese women. Fantuzzi [37] found reduced adiponectin levels in chronic low grade inflammation associated with visceral obesity, or metabolic syndrome, or type II DM, while there is an elevated adiponectin level in most chronic inflammatory and autoimmune diseases. In those (latter) patients the increased adiponectin level is independent of BMI.

A significant increase of leptin and decrease in adiponectin in E. histolytica, Strongyloides and simultaneous E. histolytica and Giardia infections has been observed. This can be attributed to the fact that those intestinal parasites may cause damage of intestinal mucosa such as ulceration, shortening of intestinal villi and dilation of crypts which can activate mesenteric lymph nodes then activate adjacent adipose tissues to secrete leptin [4]. Leptin is important in immunity to the enteric pathogens such as E. histolytica [38]. In addition to the pro-inflammatory effects on the immune system, leptin may also promote regeneration and inhibition of apoptosis of intestinal epithelium [39] as well as stimulating mucin secretion [40] and maintaining intestinal morphology [41]. Also, leptin has a role as an eosinophil survival factor in humans [42]. Eosinophil has a very significant 
role in host defense against parasitic infection. The level of eosinophilia is relative to the extent of pathology due to tissue invasion by parasites [43]. This may explain the significant increase of leptin in E. histolytica and Strongyloides, which have marked tissue invasion and pathology, and the absence of this significant increase in Giardia, Hymenolepis nana, and Oxyuris, which has no or minimal tissue invasion, and reappearance of a significant increase in both $E$. histolytica and Giardia infection because of tissue invasion by E. histolytica.

The study found a negative correlation between leptin and adiponectin in the patient group. Matsubara et al. [36] observed hypoadiponectinemia and hyperleptinemia in non-diabetic obese women, and a significant inverse relationship between plasma adiponectin and leptin concentrations that was independent of age, BUN, blood pressure, body composition, lipid and insulin resistance. Smith et al. [44] found a strong relationship between leptin, adiponectin, and abdominal obesity with increased cardiovascular disease (CVD) risk.

Many authors have reported a positive correlation between leptin and glucose in healthy nondiabetic subjects [45]. Eizadi et al. [46] also reported that serum adiponectin level is negatively correlated with fasting blood glucose and positively with insulin and $\beta$-cell function. This similarity may be due to the choice of healthy children and exclusion criteria used in this study. Also, it is known that leptin and adiponectin control blood glucose level. Decreased adipose tissue glucose metabolism leads to decreased leptin and increased adiponectin, whereas increased adipose tissue glucose metabolism after refeeding leads to the reverse [46].

In this study, plasma leptin concentration showed a positive correlation with cholesterol, triglycerides (TG) and LDL-C but a negative correlation with HDL-C in both the patient group and controls. In contrast, plasma adiponectin concentration showed a negative correlation with cholesterol, TG and LDL-C but a positive correlation with HDL-C. This agreed with $\mathrm{Wu}$ et al. [47], who found that leptin was significantly correlated with TG, LDL-C, and Apo-B but negatively correlated with HDL-C and apoprotein $A_{1}\left(\right.$ Apo- $\left.A_{1}\right)$. However, Banerji et al. [48] found no correlation between leptin and plasma lipids. These contradictory results may be due to different methodologies used. Cnop et al. [49] noted that adiponectin was negatively correlated with plasma TG and positively correlated with HDL-C. This may be attributed to the fact that adiponectin increases fat oxidation, leading to reduced levels of fatty acids and tissue triglycerides [50].

In conclusion, both leptin and adiponectin play a role in enteric parasitosis by modulating body immunity, food intake and blood chemistry. Infection of some types of intestinal parasites (Entamoeba histolytica and Strongyloides) may deregulate the secretion of leptin and adiponectin levels and also affect the absorption of some nutrients which can disturb the BMI and cause anorexia. Further studies are needed to identify their exact role in enteric parasitosis.

\section{Conflict of interest}

The authors declare no conflict of interest.

\section{References}

1. Muriuki SMK, Murugu RK, Munene E, Karere GM, Chai DC. Some gastro-intestinal parasites of zoonotic (public health) importance commonly observed in old world non-human primates in Kenya. Acta Tropica 1998; 71: 73-82.

2. Katona P, Apte KJ. The interaction between nutrition and infection. Clin Infect Dis 2008; 46: 1582-8.

3. Yip R, Sharp TW. Acute malnutrition and high childhood mortality related to diarrhea. JAMA 1993; 270: 587-90.

4. Desreumaux P, Ernst O, Geboes K, et al. Inflammatory alterations in mesenteric adipose tissue in Crohn's disease. Gastroenterology 1999; 117: 73-81.

5. Ligon BL. Infectious diseases that pose specific challenges after natural disasters: a review. In: Seminars in pediatric infectious diseases. Vol. 17. No. 1. WB Saunders, Philadelphia, USA 2006.

6. Zhang Z, Wang L, Seydel KB, et al. Entamoeba histolytica cysteine proteinases with interleukin 1 beta converting enzyme (ICE) activity cause intestinal inflammation and tissue damage in amoebiasis. Mol Microbiol 2000; 37: 542-8.

7. Peterlin BL, Bigal ME, Tepper SJ, Urakaze M, Sheftell FD, Rapoport AM. Migraine and adiponectin: is there a connection? Cephalalgia 2007; 27: 435-46.

8. Zhang Y, Proenca R, Maffei M, Barone M, Leopold L, Friedman JM. Positional cloning of the mouse obese gene and its human homologue. Nature 1994; 372: 425-32.

9. Monajemzadeh M, Ashtiani MT, Sadrian E, et al. Variation in plasma leptin levels in young Iranian children with cystic fibrosis. Arch Med Sci 2013; 9: 883-7.

10. Anagnostis P, Vakalopoulou S, Charizopoulou M, et al. Is there any association between leptin levels and bone mineral density in haemophiliac men? Arch Med Sci 2013; 9: 459-65.

11. Brennan AM, Mantzoros CS. Drug insight: the role of leptin in human physiology and pathophysiologyemerging clinical applications. Nat Clin Pract Endocrinol Metab 2006; 2: 318-27.

12. Matarese G, Moschos S, Mantzoros CS. Leptin in immunology. J Immunol 2005; 174: 3137-42.

13. Ouchi N, Kihara S, Arita Y, et al. Novel modulator for endothelial adhesion molecules: adipocyte-derived plasma protein adiponectin. Circulation 1999; 100: 2473-6.

14. Kubota N, Yano W, Kubota T, et al. Adiponectin stimulates AMP-activated protein kinase in the hypothalamus and increases food intake. Cell Metab 2007; 6: 55-68.

15. Diez JJ, Iglesias P. The role of the novel adipocytederived hormone adiponectin in human disease. Eur J Endocrinol 2003; 148: 293-300.

16. Chen J, Tan B, Karteris E, et al. Secretion of adiponectin by human placenta: differential modulation of ad- 
iponectin and its receptors by cytokines. Diabetologia 2006; 49: 1292-302

17. Ukkola O, Santaniemi M. Adiponectin: a link between excess adiposity and associated comorbidities? J Mol Med 2002; 80: 696-702.

18. Kyriazakis II, Tolkamp BJ, Hutchings MR. Towards a functional explanation for the occurrence of anorexia during parasitic infections. Anim Behav 1998; 56: 265-74.

19. Grunfeld C, Zhao C, Fuller J, et al. Endotoxin and cytokines induce expression of leptin, the ob gene product, in hamsters. J Clin Invest 1996; 97: 2152-7.

20. Considine RV, Subha MK, Heiman ML, et al. Serum immunoreactive-leptin concentrations in normalweight and obese humans. N Engl J Med 1996; 334: 292-5.

21. Tsao TS, Lodish HF, Fruebis J. ACRP30, a new hormone controlling fat and glucose metabolism. Eur J Pharmacol 2002; 440: 213-21.

22. Richie LS. An ether sedimentation technic for routine stool examinations. Bull U S Army Med Dep 1948; 8: 326.

23. Garcia LS, Bruckner DA, Brewer TC, Shimizu RY. Techniques for the recovery and identification of Cryptosporidium oocysts from stool specimens. J Clin Microbiol 1983; 18: 185-90.

24. Gomori G. A rapid one step trichrome stain. Am J Clin Pathol 1950; 20: 661-3.

25. Weber R. Improved light microscopical detection of Microsporidia spores in stool and duodenal aspirates. N Engl J Med 1992; 326: 161-6.

26. Arakaki T, Hasegawa $H$, Asato R, et al. A new method to detect Strongyloides stercoralis from human stool. Japan J Trop Med Hyg 1988; 16: 11-7.

27. Haque, RNU, Mollah IKM, Ali K, Alam A, Eubanks DL, Petri Jr WA. Diagnosis of amebic liver abscess and intes tinal infection with the TechLab Entamoeba histolytica II antigen detection and antibody tests. J Clin Microbio 2000; 38: 3235-323.

28. Barrachina MD, Martinez V, Wang L, Wei JY, Taché Y. Synergistic interaction between leptin and cholecystokinin to reduce short-term food intake in mice. Proc Natl Acad Sci USA 1997; 94: 10455-60.

29. Nicholas MM, Emilsson V, Liu YL, Cawthorne MA. Leptin action in intestinal cells. J Biol Chem 1998; 273: 26194 201.

30. Rahmanian M, Kelishadi R, Qorbani M, et al. Dual burden of body weight among Iranian children and adolescents in 2003 and 2010: the CASPIAN-III study. Arch Med Sci 2014; 10: 96-103.

31. Tilg H, Moschen AR. Adipocytokines: mediators linking adipose tissue, inflammation and immunity. Nat Rev Immunol 2006; 6: 772-83.

32. Lago F, Dieguez C, Gómez-Reino J, Gualillo O. The emerging role of adipokines as mediators of inflammation and immune responses 2007. Cytokine Growth Factor Rev 2007; 18: 313-25.

33. Lõhmus M, Moalem S, Björklund M. Leptin, a tool of parasites? Biol Lett 2012; 8: 849-52.

34. Zaralis K, Tolkamp BJ, Houdijk JK, Wylie AR, Kyriazakis I. Consequences of protein supplementation for anorexia, expression of immunity and plasma leptin concentrations in parasitized ewes of two breeds. Br J Nutr 2009; 101: 499-509.

35. Howard JK, Lord GM, Matarese G, et al. Leptin protects mice from starvation-induced lymphoid atrophy and increases thymic cellularity in ob/ob mice. J Clin Invest 1999; 104: 1051-9.

36. Matsubara M, Maruoka S, Katayose S. Inverse relationship between plasma adiponectin and leptin concentra- tions in normal-weight and obese women. Eur J Endocrinol 2002; 147: 173-80.

37. Fantuzzi G. Adiponectin and inflammation: consensus and controversy. J Allergy Clin Immunol 2008; 121: 326-30.

38. Guo X, Roberts MR, Becker SM, et al. Leptin signaling in intestinal epithelium mediates resistance to enteric infection by Entamoeba histolytica. Mucosal Immunol 2011; 4: 294-303.

39. Sukhotnik I, Coran AG, Mogilner JG, et al. Leptin affects intestinal epithelial cell turnover in correlation with leptin receptor expression along the villus-crypt axis after massive small bowel resection in a rat. Pediatr Res 2009; 66: 648-53.

40. El Homsi M, Ducroc R, Claustre J, et al. Leptin modulates the expression of secreted and membrane-associated mucins in colonic epithelial cells by targeting PKC, PI3K, and MAPK pathways. Am J Physiol Gastrointest Liver Physiol 2007; 293: G365-73.

41. Brun P, Castagliuolo I, Di Leo V, et al. Increased intestinal permeability in obese mice: new evidence in the pathogenesis of nonalcoholic steatohepatitis. Am J Physiol Gastrointest Liver Physiol 2007; 292: G518-25.

42. Conus S, Bruno A, Simon HU. Leptin is an eosinophil survival factor. J Allergy Clin Immunol 2005; 116: 1228-34.

43. Park YM, Bochner BS. Eosinophil survival and apoptosis in health and disease. Allergy Asthma Immunol Res 2010; 2: 87-101.

44. Smith J, Al-Amri M, Sniderman A, Cianflone K. Leptin and adiponectin in relation to body fat percentage, waist to hip ratio and the apoB/apoA1 ratio in Asian Indian and Caucasian men and women. Nutr Metab 2006; 10: 3-18.

45. Javor ED, Cochran EK, Musso C, Young JR, Depaoli AM, Gorden P. Long-term efficacy of leptin replacement in patients with generalized lipodystrophy. Diabetes 2005; 54: 1994-2002.

46. Eizadi M, Nazem F, Behboodi L, Khorshidi D. Correlation between serum adiponectin level and blood glucose concentration in adult asthmatic patients. Feyz, Journal of Kashan University of Medical Sciences 2012; 15 345-51.

47. Wu DM, Shen MH, Chu NF. Relationship between plasma leptin levels and lipid profiles among school children in Taiwan - the Taipei Children Heart Study. Eur J Epidemiol 2001; 17: 911-6.

48. Banerji MA, Faridi N, Atluri R, Chaiken RL, Lebovitz HE. Body composition, visceral fat, leptin, and insulin resistance in Asian Indian men. J Clin Endocrinol Metab 1999; 84: 137-44.

49. Cnop M, Havel PJ, Utzschneider KM, et al. Relationship of adiponectin to body fat distribution, insulin sensitivity and plasma lipoproteins: evidence of independent roles of age and sex. Diabetologia 2003; 46: 459-69.

50. Matsuzawa Y, Funahashi T, Kihara S, Shimomura I. Adiponectin and metabolic syndrome. Arterioscler Thromb Vasc Biol 2004; 24: 29-33. 